\title{
Veinte años de suburbanización en España (1981-2001). El perfil de sus protagonistas
}

\author{
Joaquín Susino
}

Universidad de Granada. Departamento de Sociología

jsusino@ugr.es

\section{Ricardo Duque Calvache}

Universidad de Sevilla. Departamento de Sociología

rduque@us.es

\section{Resumen}

La suburbanización, consustancial al fenómeno metropolitano, ha propiciado importantes cambios en el panorama urbano español durante las últimas décadas. En paralelo al desarrollo metropolitano, se han transformado las características de los actores individuales que tomaban parte en él. Esta investigación se centra en las variaciones en los perfiles de edad, sexo y condición sociolaboral de los protagonistas de la movilidad residencial, dentro de la cual la suburbanización no es sino el tipo de movimiento más característico. Se utilizan las matrices de movilidad de los censos de 1991 y 2001 de las áreas metropolitanas españolas, analizadas conjuntamente. Los resultados muestran un cambio en las pautas por edad de la movilidad metropolitana y, sobre todo, la generalización, durante los años noventa, de la alta movilidad residencial en todas las categorías sociales. Tendencia que muestra la creciente importancia de la movilidad como parte constitutiva de la vida urbana.

Palabras clave: movilidad residencial; áreas metropolitanas; suburbanización; estructura social.

Resum. Vint anys de suburbanització a Espanya (1981-2001). El perfil dels protagonistes

La suburbanització, consubstancial al fenomen metropolità, ha propiciat canvis importants al panorama urbà espanyol durant les darreres dècades. En paral.lel al desenvolupament metropolità, s'han transformat les característiques dels actors individuals que en formaven part. Aquesta recerca se centra en les variacions dels perfils per edat, sexe i condició sociolaboral dels protagonistes de la mobilitat residencial, dins de la qual la suburbanització no és altra cosa que el tipus de moviment més característic. Es fan servir les matrius de mobilitat de les àrees metropolitanes espanyoles, extretes dels censos dels anys 1991 i 2001 i analitzades conjuntament. Els resultats mostren un canvi en les pautes per edat de la mobilitat metropolitana y, sobretot, la generalització, durant els anys noranta, de l'elevada mobilitat residencial a totes les categories socials. Aquesta tendència evidencia la importància creixent de la mobilitat com a part constitutiva de la vida urbana.

Paraules clau: mobilitat residencial; àrees metropolitanes; suburbanització; estructura social. 
Résumé. Vingt ans de suburbanisation en Espagne (1981-2001). Le profil des acteurs

La suburbanisation, en tant qu'élément clé de la dynamique métropolitaine, a apporté des changements importants au paysage urbain de l'Espagne durant les dernières décennies. Parallèlement à la croissance des métropoles, la plupart des caractéristiques des agents individuels qui participent à ce sujet ont été transformées. Cette recherche s'intéresse à les changements dans les profils d'âge, sexe et profession des personnes qui participent à la mobilité résidentielle, un phénomène plus large dans lequel la suburbanisation est le processus le plus représentatif. Les matrices de mobilité de la population à partir des recensements de 1991 et de 2001 ont été utilisées. Les données provenant des différentes zones métropolitaines ont été agrégées et, ensuite, analysées dans son ensemble. Les résultats montrent des changements importants dans la structure par âge de la mobilité urbaine, et surtout, que les niveaux élevés de mobilité résidentielle étaient répandues dans toutes les couches sociales pendant les années 90. Cette évolution confirme le poids croissant de la mobilité dans la vie urbaine de l'Espagne.

Mots clé: mobilité résidentielle; zones métropolitaines; suburbanisation; structure sociale.

Abstract. Twenty years of suburbanization in Spain (1981-2001): A profile of its protagonists

Suburbanization, as a key part of metropolitan dynamics, has brought critical changes to the urban landscape of Spain throughout the last decades. Paralleling this metropolitan growth, the characteristics of the individual agents taking part in it were transformed. This research focuses on changes in the age, sex and occupational profiles of individuals participating in residential mobility; a wider phenomenon in which suburbanization is the most representative process. Population mobility matrixes from the 1991 and 2001 censuses have been used. Data from the different metropolitan areas have been aggregated and then analyzed as a whole. The results show that the age pattern of metropolitan mobility has changed significantly, and in particular, that high residential mobility levels were widespread in all social groups during the 90 s. This evolution confirms the growing weight of mobility in Spanish urban life.

Keywords: residential mobility; metropolitan areas; suburbanization; social structure.

\begin{tabular}{|c|c|}
\hline \multicolumn{2}{|c|}{ Sumario } \\
\hline Introducción & Efectos de la edad y el sexo \\
\hline Suburbanización y desarrollo & sobre la movilidad residencial \\
\hline metropolitano & La movilidad de las distintas categorías \\
\hline Fuentes y método & sociolaborales \\
\hline La movilidad residencial & Conclusiones \\
\hline Ireas metropolitanas españolas & Referencias bibliográficas \\
\hline
\end{tabular}




\section{Introducción $^{1}$}

Las dos últimas décadas del siglo XX fueron un periodo clave para el afianzamiento del fenómeno metropolitano en las ciudades españolas. En líneas generales, su desarrollo sigue una doble vía: la expansión espacial de las áreas más antiguas y consolidadas, y su progresiva extensión a otras ciudades, con lo cual se conforman nuevas áreas metropolitanas. El foco de interés principal en este trabajo se sitúa en la población que se dirige desde las cabeceras metropolitanas hacia los municipios del entorno inmediato, es decir, aquella que participa del fenómeno comúnmente conocido como suburbanización, pero situándolo en el marco de la movilidad residencial metropolitana tomada en su totalidad.

El tema cuenta con una larga tradición de estudio a nivel internacional, especialmente en los países anglosajones. Recorrido que parte de los modelos de crecimiento urbano de la Escuela de Chicago, hasta llegar al estudio de los factores causales de la suburbanización, en los que vale la pena detenerse. Los dos enfoques más interesantes son el de la evolución natural y el de la huida de los problemas («flight from blight»), según la denominación de Mieszkowski y Mills (1993). La primera explicación se basa en las teorías clásicas de Alonso (1964) y relaciona el crecimiento suburbano con la reducción del coste de los transportes y las mejoras en la accesibilidad. La segunda teorización toma como punto de partida la fuga de las clases medias del núcleo urbano, vinculada a motivos como la delincuencia, la contaminación urbana o la búsqueda de un estilo de vida diferente, lo que genera un aumento de sus problemas y su degradación, además de alimentar el ciclo de abandono. Pero toda teoría debe partir de una buena caracterización empírica de los hechos a explicar, lo que no siempre se hace con el rigor necesario, ni respetando tal orden. Muchos intentos de explicación parten de una idea preestablecida de cómo se produce la suburbanización, a quiénes afecta e, incluso, cuáles son sus orígenes. Algunas investigaciones (Harris y Larkham, 1999) cuestionan la imagen de la suburbanización dominante en esos trabajos, destacando que ciertas ideas deben más a una representación social que a una construcción científica.

En España, la literatura existente es más bien escasa, tanto por lo que se refiere a estudios empíricos más o menos descriptivos, como a la verificación de modelos teóricos. Algunos autores se aventuran a dar explicaciones de la suburbanización basándose en las teorías más aceptadas en otros contextos o, simplemente, atendiendo a lo que parece de sentido común, como son los diferenciales de precios de las viviendas entre las zonas centrales y las suburbanas. Pero, antes de explicar, conviene establecer los hechos y, en particular, un aspecto esencial del proceso: ¿quiénes son sus protagonistas? Este es el objeto central de nuestro trabajo.

1. Este artículo es resultado del proyecto de investigación CSO2011-29943-C03-03, financiado por el Ministerio de Ciencia e Innovación, del cual uno de los autores es investigador principal, y que forma parte del proyecto coordinado Movilidad y reconfiguración urbana y metropolitana, del Plan Nacional de I+D+i 2008-2011. 
En parte, los aspectos aquí tratados ya los hemos estudiado anteriormente en otro lugar (Susino, 2010). En aquella ocasión, el análisis se limitaba a ocho áreas metropolitanas españolas. Se describían las características de los protagonistas de su movilidad con los datos censales de 2001. En este trabajo, se amplía sensiblemente el foco de interés, tanto en lo espacial como en lo temporal. La investigación no se ha centrado en ciudades concretas, sino que comprende la totalidad de las áreas metropolitanas del país. Alcanzar esta escala es posible al partir de una delimitación con criterios homogéneos a escala nacional, que hasta hace poco no existía (Feria, 2009, 2010). Además, incorporando un segundo censo a las fuentes de datos, el de 1991, se ha conseguido abarcar un periodo de veinte años, desde 1980 hasta 2001. Lamentablemente, aún no están disponibles los datos del censo de 2011 para extender nuestro análisis otros diez años más. Sin embargo, esto tiene la ventaja de que centramos el interés en el periodo de generalización del fenómeno metropolitano en España, antes de la fase álgida de la burbuja inmobiliaria, que se desinflará a partir de 2007.

Inicialmente, es necesario discutir brevemente en qué medida es aplicable a nuestro país el concepto de suburbanización, justificando el uso que aquí hacemos de él. Esto se realiza en el siguiente epígrafe. En el tercero, se abordan los problemas metodológicos, con especial referencia a tres cuestiones: las fuentes estadísticas para su estudio, la definición de las áreas metropolitanas y la metodología seguida en el análisis. Presentadas las áreas metropolitanas y el grado de desarrollo de su proceso de suburbanización, objetivos del cuarto apartado, podemos entrar a analizar los factores que hacen evolucionar la movilidad. En el epígrafe quinto, se discute en qué medida sexo y edad afectan a la distribución y a la intensidad de los desplazamientos. En el sexto, vemos cómo los patrones de movilidad se han visto afectados por los cambios en la estructura social, que analizamos a partir de la condición sociolaboral. En el apartado de conclusiones, además de sintetizar los principales hallazgos de nuestra investigación, se plantean las cuestiones que, a nuestro parecer, deben orientar nuestras investigaciones futuras sobre el tema.

\section{Suburbanización y desarrollo metropolitano}

Aunque nuestro trabajo se centre en sus protagonistas, no podemos dejar de referirnos a los cambios en la forma urbana asociados a lo que venimos en llamar «suburbanización». Que tales cambios constituyen, en sí mismos, un problema conceptual y teórico, lo pone de manifiesto la diversidad de nociones que se han propuesto en los últimos decenios para referirse a ellos (Vicente, 2003).

La dificultad para alcanzar un consenso terminológico se agranda al comprobar cómo un mismo concepto puede cambiar su significado al ser traducido a otro idioma ${ }^{2}$. Un ejemplo paradigmático de este problema podría ser el término suburbio. Aunque de origen anterior, se extendió a partir del siglo XIX

2. Es decir, al ser trasladado a otro contexto, ya que la carga significativa no la da tanto la palabra como el entorno y las circunstancias históricas en que ésta se ha empleado. 
en castellano para designar los barrios alejados del centro de las ciudades, que surgieron para alojar a la población trabajadora, frecuentemente de origen rural, atraída por el crecimiento urbano que impulsó la revolución industrial y el moderno proceso de urbanización. Más en concreto, se aplicaba a los barrios más pobres y degradados.

La actual noción de «lo suburbano» se aleja, sin embargo, de esas connotaciones peyorativas y se aplica a los crecimientos residenciales, frecuentemente de clases medias y de baja densidad, situados a las afueras de las ciudades. Este cambio semántico se debe a que su raíz ya no parece ser el término castellano suburbio, sino el suburb anglosajón. Por esta razón, en el uso cotidiano, el suburbio y lo suburbano están desligados. Para referirnos a los desarrollos suburbanos posteriores a la Segunda Guerra Mundial, no utilizamos la palabra suburbio, puesto que sigue teniendo una connotación negativa, vinculada a los barrios periféricos pobres.

Una literatura crítica con lo que se han llamado los «mitos de la suburbanización» (Harris y Larkham, 1999) pone de manifiesto, por un lado, la antigüedad del fenómeno y, por otro, la diversidad de sus formas. El origen del residencial de baja densidad acomodado americano se remontaría, para estos autores, al cambio del siglo XIX al XX. Y es importante destacar la existencia de suburbs obreros, vinculados a la descentralización de la industria y apoyados en sistemas de transporte que, en su origen, eran públicos. El debate, en cualquier caso, no está cerrado, porque, frente a quienes insisten en la complejidad del fenómeno (Mieszkowski y Mills, 1993; Kim, 2007), están los que argumentan su relativa simplicidad (Glaeser y Kahn, 2003).

Es tras la Segunda Guerra Mundial cuando el fenómeno se generaliza y afecta masivamente a las capas medias de la sociedad americana. Este desarrollo reciente y a gran escala de procesos de suburbanización homogéneos morfológicamente (e incluso socialmente), basados en viviendas unifamiliares, preferentemente aisladas, es típicamente norteamericano y acaba convirtiéndose en el paradigma de lo suburbano. Esta forma urbana, acompañada de un estilo de vida particular, se convierte en una seña de identidad de la clase media estadounidense que pronto se difunde y se integra en los imaginarios culturales del resto del mundo.

En Europa, la suburbanización se ha producido a una escala mucho menor $y$, en cualquier caso, adquiere otras formas, tanto por su morfología urbana como por sus características sociales. Señala Dematteis (1998) que existe una suburbanización europea continental diferenciable de la americana, aunque también responde al imaginario social de lo suburbano antes descrito. Algunos académicos pretenden distinguir entre la periurbanización, que sería la forma de extensión de la urbanización en la Europa continental (Mongin, 2006) 3 , y la suburbanización, que sería más específicamente anglosajona. Otros autores hacen un uso bastante extensivo de la periurbanización (Entrena, 2005), que la identifican con la ciudad desconcentrada, dispersa o difusa. Parece más

3. El uso de periurbanización en lugar de suburbanización es frecuente en Francia. 
acertado el planteamiento de García Palomares y Pozo (2010), para quienes lo periurbano no es alternativo a lo suburbano, sino lo que se sitúa más allá de lo urbano metropolitano, en coronas sucesivas.

A estos usos diferentes de las palabras vienen a unirse nuevas nociones. En el caso de la contraurbanización, se destaca el crecimiento de lo "no urbano", la ruptura de la tendencia hacia la concentración. La dificultad estriba en definir tal ámbito. Analizando el caso gallego, Ferrás (2011) señala que la suburbanización y la contraurbanización generan nuevas formas de urbanización desconcentrada en las periferias de las ciudades, sin que sea fácil identificar las diferencias, si las hay, entre ambos procesos. Mientras que para Burriel et al. (1998) la contraurbanización ocurre más allá de una segunda corona metropolitana que estaría experimentando un proceso de suburbanización.

Otros autores han adoptado el término, también de origen norteamericano, urban sprawl, que parecen preferir al de suburbanización. Para algunos no es sino el corolario de la suburbanización (Yu et al., 2004). Desde otro punto de vista, sería una fase superior, cualitativamente distinta y mucho más universal que la suburbanización. También en los últimos años, se ha popularizado el concepto de ciudad difusa. Aunque la definición original de Indovina (2004) se refiere a una forma urbana específica en ciertas zonas de Italia, después se ha trasladado a otros contextos que poco tienen que ver con ellas. El concepto de ciudad dispersa parece acomodarse mejor a los aspectos morfológicos de la trama urbana, al hecho de que estos desarrollos suburbanos se realizan con frecuencia al margen de los antiguos cascos consolidados de los municipios periféricos.

Lo que se deduce de esta confusión terminológica y de la literatura crítica con los «mitos» de la suburbanización es que el proceso puede adoptar formas muy diferentes y estar impulsado por factores específicos de los contextos sociohistóricos y territoriales en que se produce.

Lejanos ya sus míticos orígenes norteamericanos, la suburbanización, entendida de una u otra forma, se ha extendido por todo el mundo. Aun con notables diferencias, el fenómeno no se limita a los países más desarrollados. Recientemente, se ha constatado su emergencia y desarrollo en los países postcomunistas del este de Europa (Zebik, 2011) y en los países en vías de desarrollo. No solo en los de economías emergentes del sudeste de Asia, sino también en casi todos los latinoamericanos e incluso en África. Aunque en Latinoamérica hay una suburbanización de clases trabajadoras pobres, hay autores que, con este término, parecen referirse únicamente a la de las clases medias altas y en unidades morfológicamente muy distintivas, las comunidades cerradas (Arizaga, 2004), con lo que parece hacerse una traslación de esos componentes míticos de la suburbanización a otros contextos económicos y sociales. En este sentido, algunos autores identifican la suburbanización como una tendencia universal ligada a la globalización económica, pero también cultural, más específicamente, de las prácticas de consumo, ligadas incluso a la extensión del «sueño americano» (Leichenko y Solecki, 2005). 
Sin duda, el desarrollo del fenómeno metropolitano, que sí parece ser universal, va ligado a distintas formas de extensión de la ciudad en el territorio ${ }^{4} \mathrm{y}$ presenta diversas facetas, materiales y simbólicas. Atañe a la morfología urbana, pero no responde a un único tipo de ella, puesto que es distinta en densidades, tipologías edificatorias y en su contigüidad con el centro. Además, comprende una vertiente ideológica, un estilo de vida y unos valores, cuyas características varían con los contextos locales.

No pretendemos profundizar en tales debates: nuestro interés se centra exclusivamente en determinar qué características demográficas y sociales tienen quienes protagonizan ese movimiento de suburbanización en las áreas metropolitanas españolas desde 1980 hasta 2001. Y pretendemos hacerlo en el marco de la movilidad residencial metropolitana tomada en su conjunto, como una parte no desligable de ella. Para los fines de este trabajo, llamaremos «suburbano» a todo el desarrollo urbano que se produce en las coronas metropolitanas, con independencia de sus características morfológicas. Y calificaremos de suburbanización al movimiento de la población que cambia de residencia dentro de las áreas metropolitanas, desde las ciudades centrales o cabeceras hacia las coronas metropolitanas.

En cuanto a los precedentes concretos de esta investigación, cabe destacar el repaso que realiza García Coll (2009) sobre el estudio de las migraciones interiores en España. Esta autora destaca que los análisis de la suburbanización se han centrado en la descripción del proceso y su incidencia territorial. Algunos han prestado atención a la repercusión de factores demográficos, como la edad (Pujadas, 2009), otros se centran en las motivaciones de quienes se suburbanizan (Miralles-Guasch et al., 2007), pero pocos han analizado características sociales y, en todo caso, focalizando el trabajo en áreas concretas (Módenes, 2001; Pujadas y García Coll, 2007; López Gay y Recaño, 2008). En esta investigación, trataremos precisamente de cubrir esa laguna, pero sin profundizar en las características de cada ciudad para poder tener una visión de conjunto. Se pretende, en suma, establecer el contexto general del fenómeno de la suburbanización de las décadas de 1980 y 1990 en España, ya que este es el marco en el que se deben entender los análisis a nivel local.

\section{Fuentes y método}

Si el panorama teórico es complejo, no lo es menos la aplicación práctica de tales planteamientos. Actualmente, coexisten diversas formas de delimitar las áreas urbanas, sin que haya un acuerdo acerca de la mejor manera de emprender tal tarea. Esta situación condiciona especialmente los estudios que intentan realizar comparaciones internacionales (Kabisch y Haase, 2011). En España,

4. Aunque la suburbanización es un proceso más específicamente ligado a la forma monocéntrica de desarrollo metropolitano, también es observable en los desarrollos polinucleares metropolitanos, apoyados en una red de centros previamente existentes de tamaños o importancia más o menos comparables. 
a diferencia de otros países, no hay una definición estadística oficial de qué es un área metropolitana. Sin embargo, recientemente, varios proyectos abordan la delimitación de las áreas urbanas españolas (Ministerio de Vivienda, 2006; Ruiz, 2012). En este artículo, nos basamos en los trabajos publicados por Feria (2009, 2010), que caracterizan y delimitan el fenómeno metropolitano en el conjunto del territorio español a partir de la movilidad cotidiana por razones laborales, la variable más utilizada a estos efectos a nivel internacional. Esta delimitación constituye la base de nuestro trabajo.

Una vez establecido el ámbito de lo metropolitano, podemos adentrarnos en la movilidad que se produce en el interior de estos espacios. Dos son las fuentes estadísticas disponibles para el análisis de la movilidad residencial en el interior de las áreas urbanas: los censos de población y las estadísticas de variaciones residenciales (EVR). En realidad, estas últimas no permiten el análisis que pretendemos realizar por varias razones. Primero, las EVR no ofrecen datos de movilidad intramunicipal, por lo que no hacen posible estudiar el conjunto de la movilidad residencial metropolitana ${ }^{5}$. Segundo, las estadísticas derivadas del padrón solo permiten analizar variables puramente demográficas, que son las únicas incluidas en tales registros administrativos, pero no variables sociales como la relación con la actividad o la condición socioeconómica ${ }^{6}$. Por último, las EVR no permiten analizar la evolución de la movilidad en el medio o largo plazo, dado que su cobertura ha ido cambiando con los años y es imposible saber en qué momento los datos permitirían analizar la evolución real de las migraciones sin que se deba a los propios cambios que se han producido en la fuente (Susino, 2011).

Por estas razones, la única posibilidad de análisis la ofrecen los censos. Estos tienen la ventaja de su mayor estabilidad en el tiempo, puesto que las preguntas sobre migraciones son parecidas en uno y otro censo y porque contienen no solo información sobre las características demográficas de quienes se mueven, sino también sobre las sociales. Lo que no quiere decir que estén exentos de problemas. Debemos destacar dos:

- En primer lugar, la pregunta utilizada es la referida al lugar de residencia cuando se hizo el censo anterior ${ }^{7}$ y las características demográficas y sociales de quienes se mueven se refieren al momento censal, no al momento en que se produce el cambio de residencia (García Coll, 2009).

- En segundo lugar, la movilidad intramunicipal se deriva de preguntas distintas en uno y otro censo. En el de 1991, de la propia pregunta sobre el lugar de residencia en 1981, que incluía las opciones «mismo municipio, mismo domicilio» y «mismo municipio, otro domicilio». En el de 2001, se

5. Si bien las altas y las bajas padronales por cambios de domicilio lo permitirían, de hecho, tales datos no se incluyen en las estadísticas publicadas por el INE.

6. El nivel educativo también se incluye, pero su uso plantearía muchos problemas, dado que solo se actualiza para los que se mueven.

7. Es decir, 10 años antes en el censo de 1991 y 10 años y 8 meses en el de 2001. 
ha tenido que recurrir a otra pregunta, que inquiere desde cuándo ocupa el hogar la vivienda, y se clasifican como móviles intramunicipales a quienes, en 1991, vivían en el mismo municipio pero en una vivienda a la que el hogar llegó más tarde.

Respecto al primer problema, cabe decir que la movilidad migratoria y residencial no es tanto un acontecimiento aislado, como un proceso que se enmarca en trayectorias vitales como proyecto. Esto quiere decir que la situación laboral y la condición socioeconómica posterior al cambio pueden ser tan relevantes como la previa, porque la movilidad residencial va con frecuencia ligada a ese cambio sociolaboral, ya sea este el factor que la provoca, la consecuencia que se busca o lo que la hace posible (Morrison y Clark, 2011). Hemos calculado, a partir de datos del censo de 2001, el número medio de años transcurridos entre el momento del cambio y la inscripción censal. Se sitúa, para toda España, entre los 4,5 y los 5 años, excepto para los inmigrantes provenientes del extranjero, cercanos a los 3 años. La diferencia de tiempo transcurrida quizás sea algo mayor de la conveniente, pero no disparatada. La movilidad de los componentes de cualquier categoría sociolaboral debe interpretarse, por tanto, como la de quienes se mueven a la vez en el espacio geográfico y en el social hacia esa categoría y esa nueva residencia.

Respecto al segundo problema, la comparabilidad de los censos de 1991 y 2001, afecta a la distribución entre sedentarios y móviles de quienes vivían en el mismo municipo, aunque no a los cambios intermunicipales que responden a preguntas idénticas, si bien a periodos ligeramente distintos. El procedimiento a que nos obliga el censo de 2001 tiende a subestimar a los móviles, en la medida en que no identifica como tales a quienes se han movido a una vivienda en que ya había un hogar establecido (por ejemplo: quien se va a vivir a casa de su nueva pareja). Pero también tiende a sobrestimarla (en relación con el otro censo) cuando el hogar se desplaza entre ambos censos y luego vuelve a la misma vivienda; en cuyo caso, el censo de 1991 los calificaría como sedentarios y el de 2001, como móviles. No es posible saber cuál de estos efectos es mayor ni si se compensan. Solo cabe lamentarse de la desafortunada opción de cambiar la pregunta entre ambos censos.

La elección de la pregunta sobre el lugar de residencia en la fecha del censo anterior parece que da resultados más consistentes que la referida al último lugar de residencia o última migración, por las razones expuestas en otro lugar (Susino, 2011). Además, recoge los cambios estructurales y se ve menos afectada por los más coyunturales. La ventaja de la pregunta sobre la última migración es que permitiría estudiar la edad en el momento del cambio, pero no la condición sociolaboral, que, en cualquier caso, sería la del momento censal, por lo que esa ventaja se desvanece, ya que sería incongruente analizar cada variable en referencia a momentos distintos.

A pesar de estas dificultades, debemos hacer hincapié en las posibilidades de análisis que nos ofrece nuestro sistema estadístico frente a otros. Por las 
Tabla 1. Grupos de población según origen y destino de su movilidad residencial

\begin{tabular}{lll}
\hline Ámbito de origen & Movilidad según destino & Denominación del grupo \\
\hline Cabeceras & Sedentarios & Sedentarios cabecera \\
& Mismo municipio & Intramunicipales cabecera \\
& Otro municipio (cabecera) & Entre cabeceras \\
& Otro municipio (corona) & Suburbanización (cabecera a corona) \\
\hline Coronas & Sedentarios & Sedentarios corona \\
& Mismo municipio & Intramunicipales corona \\
& Otro municipio (cabecera) & Corona a cabecera \\
& Otro municipio (corona) & Corona a corona \\
\hline
\end{tabular}

Fuente: elaboración propia.

variables consideradas y por el nivel de desagregación territorial de los datos, estamos en mucha mejor situación que, por ejemplo, los británicos (Champion y Fisher, 2003; Champion y Coombes, 2007) ${ }^{8}$.

La apuesta por los censos como fuente descansa, pues, en la idea de que, para entender la suburbanización de los distintos grupos sociales, es necesaria considerarla en el marco de la totalidad de la movilidad residencial metropolitana y, junto a la inmovilidad, el sedentarismo. Consideramos imprescindible ver las diferencias entre los que participan en los diferentes tipos de desplazamientos.

Siendo la suburbanización el tema que nos ocupa, los dos ámbitos básicos que vamos a contemplar son la cabecera (el núcleo principal, que da nombre a la aglomeración urbana) frente a la corona, formada por aquellos municipios circundantes que se han integrado en la dinámica metropolitana9. En función de esta distinción entre centros o cabeceras y coronas, tenemos ocho posibles situaciones referidas al ámbito de origen y de destino ${ }^{10}$, que, en adelante, serán denominadas tal y como se recoge en la tabla 1.

En cuanto a las variables que van a ser tenidas en cuenta, son de dos tipos: demográficas y sociales. Las primeras incluyen la edad (agrupada quinquenalmente) y el sexo. Las segundas, las variables censales referidas a la condición socioeconómica y la relación con la actividad, las vamos a integrar en una

8. Veremos si el censo de 2011, dada su base muestral, permite un análisis territorialmente tan desagregado como los dos censos anteriores.

9. Este planteamiento se acomoda mejor a las áreas centralizadas, basadas en una sola ciudad que progresivamente extiende su influencia hacia el entorno, que a otro tipo de áreas. En el caso de las áreas con estructuras más complejas, en las que varios núcleos, aunque sean de tamaños muy diferentes, actúan como centros respecto de sus entornos inmediatos y todos ellos en red, hemos optado por considerarlos a todos ellos como cabeceras. De ahí que haya movimientos en la tabla 1 «entre cabeceras», pero su número es tan pequeño y afecta a tan pocas áreas que no los estudiaremos en este trabajo.

10. De esta clasificación por movimientos quedan excluidos todos los que tienen origen o destino fuera de las áreas metropolitanas o en áreas metropolitanas distintas. Téngase en cuenta que solo se analiza aquí la movilidad residencial en el interior de las áreas y no otros componentes de su dinámica demográfica. 
clasificación única bajo la denominación de «condición sociolaboral». El interés por integrar estos dos tipos de características de la población se debe a la importancia que, desde hace décadas, otorgan a las primeras las teorías del ciclo vital (Rossi, 1955) y al hecho evidente de que la movilidad espacial no se distribuye uniformemente a través del espacio social.

En la evolución de la movilidad, estas variables interactúan entre sí, con los cambios en el tamaño de las poblaciones afectadas, con su composición por sexo y edad y con las variaciones que se producen en la propia estructura social. En este trabajo, no intentamos cuantificar la importancia de cada uno de estos efectos, solamente pretendemos identificar las relaciones entre ellos, para lo que nos servimos de las usuales técnicas de análisis demográfico. En el cálculo de las tasas de movilidad, los denominadores comprenden la población residente en las áreas metropolitanas (y en las dos subdivisiones básicas: cabeceras y coronas) al final de cada periodo, pero que al principio del mismo también vivía en la misma área, sometida, por tanto, al riesgo de cambiar de residencia dentro del área ${ }^{11}$. También se han calculado índices sintéticos de movilidad a partir de tales tasas, aunque, en realidad, se opera con proporciones y no con tasas en sentido demográfico ${ }^{12}$.

\section{La movilidad residencial en las áreas metropolitanas españolas}

De acuerdo con la delimitación de las áreas metropolitanas utilizada (Feria, 2010), algo más de las dos terceras partes de la población española vive en áreas metropolitanas. Se identifican 46 en total. La población de estas aglomeraciones oscila entre los poco más de 100.000 habitantes de Benidorm y los más de cinco millones y medio de Madrid-Alcalá de Henares. La tabla 2 detalla la población y algunas características básicas de cada una de ellas. Tabla que nos permite constatar algo que, por otra parte, resulta obvio a simple vista: la enorme heterogeneidad existente entre las 46 áreas $^{13}$.

11. Excluyen, por tanto, a todas las personas no susceptibles de cambiar de residencia en cada periodo, los inmigrantes provenientes del extranjero o de fuera de cada área y los que no habían nacido cuando se hizo el censo anterior, así como aquellos para los que no constan sus movimientos (los que habitan en viviendas colectivas). Bien entendido que la población sometida al riesgo de cambiar de residencia es función de la pregunta censal utilizada. Los inmigrantes y emigrantes a cada área, así como los menores de 10 años, han podido cambiar dentro de las áreas durante cada periodo, pero no pueden aparecer como móviles internos en relación con el lugar de residencia 10 años antes, puesto que la pregunta no mide migraciones, sino migrantes, por lo que se excluyen de los denominadores de las tasas.

12. Son proporciones, puesto que se comparan dos variables efectivas, cuando las tasas demográficas ponen en relación un flujo con un efectivo medio. Además, como los periodos intercensales son de distinta duración, se ha tenido en cuenta tal hecho para calcular los «migrantes anuales medios». Por último, tales índices no son completos, puesto que siempre faltan los movimientos en los primeros 10 años de vida.

13. Esta delimitación refleja, básicamente, una intensa relación de movilidad por razón de trabajo entre municipios en el año 2001, lo cual constituye, en este sentido, una unidad funcional supramunicipal. 
Tabla 2. Indicadores básicos de las áreas metropolitanas españolas

\begin{tabular}{|c|c|c|c|c|c|c|c|}
\hline & \multicolumn{4}{|c|}{ Censo de 2001} & \multicolumn{3}{|c|}{ Variación 1991-2001 } \\
\hline & $\begin{array}{l}\text { Población } \\
\text { en } 2001\end{array}$ & $\begin{array}{l}\text { Número de } \\
\text { municipios }\end{array}$ & $\begin{array}{l}\text { Porcentaje } \\
\text { población } \\
\text { corona }\end{array}$ & $\begin{array}{c}\text { Porcentaje } \\
\text { movilidad } \\
\text { intermunic. }\end{array}$ & $\begin{array}{l}\text { Población } \\
\text { total }\end{array}$ & $\begin{array}{l}\text { Población } \\
\text { corona }\end{array}$ & $\begin{array}{c}\text { Movilidad } \\
\text { intermunicipal }\end{array}$ \\
\hline Total & 27.514 .628 & 1.227 & 45,3 & 21,0 & 6,5 & 16,3 & 26,8 \\
\hline Bilbao & 1.131 .564 & 93 & 69,1 & 27,3 & $-2,2$ & $-0,1$ & 8,2 \\
\hline Tarragona & 316.638 & 29 & 64,3 & 16,2 & 13,5 & 21,2 & 49,7 \\
\hline Barcelona-Sabadell & 4.340 .618 & 130 & 61,1 & 29,8 & 3,1 & 12,2 & 46,5 \\
\hline Donosti & 431.696 & 27 & 58,7 & 17,6 & 1,4 & 0,3 & $-3,3$ \\
\hline Girona & 172.965 & 31 & 56,7 & 21,8 & 10,0 & 10,8 & 7,8 \\
\hline Santa Cruz de Tenerife & 430.858 & 13 & 56,3 & 21,2 & 6,7 & 19,3 & $-0,9$ \\
\hline Santiago & 201.332 & 18 & 55,2 & 21,2 & 5,8 & 8,2 & 39,2 \\
\hline Valencia & 1.594 .762 & 74 & 53,7 & 21,5 & 5,0 & 12,4 & 27,9 \\
\hline Santander & 388.734 & 29 & 53,5 & 27,2 & 1,3 & 8,5 & 33,9 \\
\hline Algeciras & 213.737 & 6 & 52,5 & 6,5 & 4,0 & 7,9 & $-18,6$ \\
\hline Ferrol & 163.404 & 10 & 52,3 & 18,8 & $-3,7$ & $-1,3$ & $-4,8$ \\
\hline Castellón & 305.651 & 20 & 51,7 & 10,6 & 12,6 & 15,5 & $-20,4$ \\
\hline Granada & 497.945 & 47 & 51,7 & 27,8 & 9,8 & 29,9 & 50,1 \\
\hline Manresa & 132.095 & 17 & 51,6 & 17,9 & 1,7 & 8,0 & 27,8 \\
\hline Pontevedra & 154.010 & 13 & 51,3 & 11,4 & $-0,3$ & $-4,5$ & $-21,7$ \\
\hline Benidorm & 104.884 & 7 & 50,5 & 10,8 & 16,0 & 11,4 & 22,5 \\
\hline Sevilla & 1.369 .708 & 49 & 50,0 & 17,5 & 8,2 & 17,3 & 23,2 \\
\hline Las Palmas de Gran Canaria & 709.191 & 18 & 50,0 & 18,0 & 9,5 & 20,9 & 6,2 \\
\hline Vigo & 550.531 & 28 & 49,1 & 14,2 & 1,8 & 2,6 & $-0,7$ \\
\hline A Coruña & 463.339 & 23 & 49,0 & 24,6 & 4,1 & 14,8 & 50,6 \\
\hline Cádiz-Jerez & 602.809 & 7 & 47,5 & 9,8 & 2,6 & 14,8 & 23,8 \\
\hline Madrid-Alcalá de Henares & 5.623 .784 & 171 & 44,6 & 29,1 & 10,4 & 30,7 & 26,1 \\
\hline Marbella & 174.862 & 10 & 42,8 & 5,0 & 20,8 & 17,0 & 0,3 \\
\hline Ourense & 178.732 & 25 & 39,8 & 15,1 & 0,5 & $-3,6$ & 42,7 \\
\hline Pamplona & 294.843 & 25 & 37,6 & 26,5 & 13,2 & 38,6 & 44,6 \\
\hline Avilés-Gijón-0viedo & 871.859 & 28 & 36,8 & 15,8 & $-0,9$ & $-5,1$ & $-13,3$ \\
\hline Huelva & 224.645 & 11 & 36,7 & 10,5 & 5,7 & 18,0 & 32,0 \\
\hline Málaga & 826.038 & 19 & 36,5 & 15,1 & 11,6 & 38,6 & 37,8 \\
\hline León & 203.400 & 20 & 35,6 & 22,5 & $-0,7$ & 17,6 & 48,3 \\
\hline Almería & 241.046 & 9 & 31,0 & 11,7 & 20,9 & 67,1 & 86,3 \\
\hline Murcia & 529.467 & 12 & 30,0 & 7,9 & 14,0 & 17,3 & $-8,5$ \\
\hline Lleida & 158.089 & 23 & 29,0 & 11,4 & 1,8 & 6,7 & 46,6 \\
\hline Palma de Mallorca & 470.000 & 20 & 29,0 & 14,5 & 20,3 & 43,7 & 23,9 \\
\hline Alicante & 381.502 & 7 & 25,4 & 12,1 & 14,2 & 42,2 & 34,5 \\
\hline Valladolid & 395.258 & 28 & 19,9 & 17,4 & 3,0 & 47,9 & 100,9 \\
\hline Salamanca & 194.567 & 19 & 19,6 & 18,4 & 5,3 & 74,2 & 98,2 \\
\hline Logroño & 165.327 & 19 & 19,5 & 8,6 & 9,2 & 12,8 & 27,7 \\
\hline Elche & 239.335 & 3 & 18,6 & 2,1 & 6,0 & 18,5 & 1,6 \\
\hline Badajoz & 163.922 & 10 & 18,5 & 2,0 & 11,3 & 21,1 & $-0,7$ \\
\hline Zaragoza & 684.490 & 31 & 10,2 & 5,4 & 5,0 & 21,3 & 49,6 \\
\hline Vitoria & 238.114 & 19 & 8,9 & 7,3 & 6,6 & 23,1 & 63,3 \\
\hline Cartagena & 199.227 & 2 & 7,3 & 1,8 & 9,6 & 4,4 & $-20,7$ \\
\hline Jaén & 119.852 & 3 & 6,1 & 1,3 & 9,2 & 14,5 & 26,0 \\
\hline Córdoba & 327.788 & 5 & 6,0 & 1,1 & 2,0 & 0,7 & 4,7 \\
\hline Burgos & 175.282 & 15 & 5,2 & 5,8 & 5,7 & 46,2 & 144,4 \\
\hline Albacete & 156.728 & 4 & 5,0 & 1,0 & 15,8 & 45,4 & $-22,4$ \\
\hline
\end{tabular}

Fuente: elaboración propia a partir de los datos de los censos de 1991 y 2001 (INE) y la delimitación de las áreas de Feria (2010). Las áreas están ordenadas por su porcentaje de población suburbana y aparecen remarcadas las cinco mayores. 
Ordenadas en función de la proporción de población que vive en la corona metropolitana, en la zona suburbana, vemos que hay áreas en que la población disminuyó entre 1991 y 2001, casi siempre las mismas en que disminuyó la población de las coronas. Hay también casos en que la movilidad intermunicipal pierde peso sobre la movilidad total, aunque la tendencia general es justo la contraria, en un marco de fuerte incremento de la movilidad residencial intrametropolitana (ver tabla 3). Por eso parece difícil aplicar, al conjunto de todas las áreas urbanas, un modelo de evolución urbana en que, a la suburbanización, e incluso a la desurbanización, seguiría un proceso de reurbanización (Van den Berg et al., 1982). En el periodo analizado, no hay evidencias de un proceso de recentralización (Nel·lo, 2007), especialmente cuando se estudia el conjunto de todas las áreas y no solo las más grandes.

Desde una perspectiva general, los datos censales revelan un enorme aumento de la movilidad residencial en el seno de las áreas metropolitanas entre las décadas de 1980 y 1990 . A pesar de los problemas que entraña la comparación de los censos de 1991 y 2001, esta conclusión se impone como un hecho cierto. El enorme aumento de la movilidad residencial intramunicipal no puede deberse únicamente a un efecto estadístico de los distintos sistemas empleados en su medición. La población se movía más en los noventa, globalmente y en casi todos los tipos de desplazamientos (tabla 3). La excepción son los traslados desde la corona hasta la cabecera, por las razones que se verán más adelante.

Para el conjunto de todas las áreas, es palpable el desarrollo de una auténtica dinámica metropolitana. No solamente aumentaron muy considerablemente los que salían de la cabecera a la corona (cerca del 50\%), sino que, además, se multiplicó la movilidad de la corona, ya sea dentro de los mismos municipios o en municipios distintos. Con la consolidación de estas relaciones transversales, los núcleos de la corona dejan de ser meros satélites de la cabecera. Forman parte crucial del proceso de desarrollo metropolitano y de expansión de lo

Tabla 3. Evolución de la movilidad residencial metropolitana

\begin{tabular}{lrrrrrrrr}
\hline & \multicolumn{3}{c}{ Móviles metropolitanos } & & \multicolumn{3}{c}{ Índices sintéticos de movilidad } \\
\cline { 2 - 3 } & \multicolumn{1}{c}{1991} & \multicolumn{1}{c}{$\mathbf{2 0 0 1}$} & Variación & & $\mathbf{1 9 9 1}$ & & $\mathbf{2 0 0 1}$ & Variación \\
\hline Intramunicipal cabecera & 3.262 .008 & 3.978 .323 & 14,3 & & 1.909 & 2.056 & 7,7 \\
Suburbanización & 575.564 & 889.589 & 44,9 & & 322 & 443 & 37,4 \\
Intramunicipal corona & 1.586 .065 & 2.638 .505 & 56,0 & & 1.353 & 1.832 & 35,4 \\
Corona a corona & 449.911 & 622.872 & 29,8 & & 362 & 408 & 12,9 \\
Corona a cabecera & 237.926 & 225.461 & $-11,2$ & & 205 & 157 & $-23,3$ \\
\hline Movilidad total & 6.134 .338 & 8.376 .895 & 28,0 & & 2.115 & 2.463 & 16,4 \\
\hline
\end{tabular}

Fuente: elaboración propia a partir de los censos de población de 1991 y 2001.

Nota: para el cálculo de los porcentajes de variación, se ha tenido en cuenta que el periodo a que se refiere el censo de 2001 es 8 meses más largo que el del censo de 1991. El índice sintético de movilidad representa el número de veces que una cohorte ficticia de mil individuos cambiaría de vivienda, dentro de un área metropolitana, desde los 10 años hasta el final de la vida. 
suburbano, aunque no se trate de movimientos de descentralización de población en sentido estricto ${ }^{14}$.

De los tres factores indicados, la tabla 3 permite ver que solo una parte, aunque muy importante, responde a un aumento real de la propensión a la movilidad de los ciudadanos, la que reflejan los índices sintéticos que, como es sabido, eliminan los efectos del tamaño de la población y de la estructura de edades en la medición de la intensidad de los fenómenos demográficos. El resto del aumento de la movilidad absoluta se debe parcialmente al crecimiento del tamaño de la población, pero este efecto es débil en los movimientos que tienen origen en las cabeceras de las áreas, cuya población aumentó menos del $4 \%$ entre 1991 y 2001 . Sí es importante, sin embargo, en los movimientos con origen en las coronas metropolitanas, porque su población aumentó un 14\%.

Pero el incremento general de la movilidad no es explicado exclusivamente por el aumento de los índices de movilidad ni por el aumento de la población, sino también por los cambios en las estructuras de edades de la población y en el calendario de la propia movilidad. Debemos, por tanto, analizar más detenidamente la movilidad en función de las estructuras demográficas de edad y sexo.

\section{Efectos de la edad y el sexo sobre la movilidad residencial}

Un primer vistazo a las tasas de movilidad por edad y sexo revela la importancia de estas variables, especialmente la primera, que es el elemento clave para teorías como la del ciclo vital (Rossi, 1955). Existe una pauta básica de movilidad por edades para ambos sexos. En términos absolutos, los más móviles son los adultos jóvenes, sea cual sea el tipo de cambio, y los menos móviles, los ancianos. Podemos considerar, por tanto, que la población joven es la gran protagonista de la movilidad residencial y, en concreto, de la suburbanización. Pero esta pauta general varía de forma significativa entre 1991 y 2001, y se modula en función del ámbito del traslado, por lo que es necesario un análisis más detallado.

Si bien el sexo tiene un peso bastante menor en la configuración de la movilidad que la edad, es importante señalar un hecho relevante. En la figura 1 , es fácil apreciar un ligero desfase en las tasas entre hombres y mujeres. Según el censo de 1991, las mujeres presentan mayor movilidad entre los 20 y los 29 años, y los hombres, por encima de los 30 y hasta los 59. Según el censo de 2001, la mayor movilidad de las mujeres se prolonga hasta el grupo de 30 a 34 años y la de los hombres, desde los 35 hasta los 69 años. La razón es que buena parte de los cambios de residencia son de parejas en que los varones suelen tener entre dos y tres años más que las mujeres. Además, las jóvenes tienden a emanciparse antes que los varones, incluso cuando lo hacen de forma individual y no en pareja.

14. No obstante, en las áreas maduras y estructuralmente más complejas, parte de los movimientos corona a corona están formados por desplazamientos de una primera a una segunda corona, que, desde otro punto de vista, pueden interpretarse como un proceso de desconcentración. 


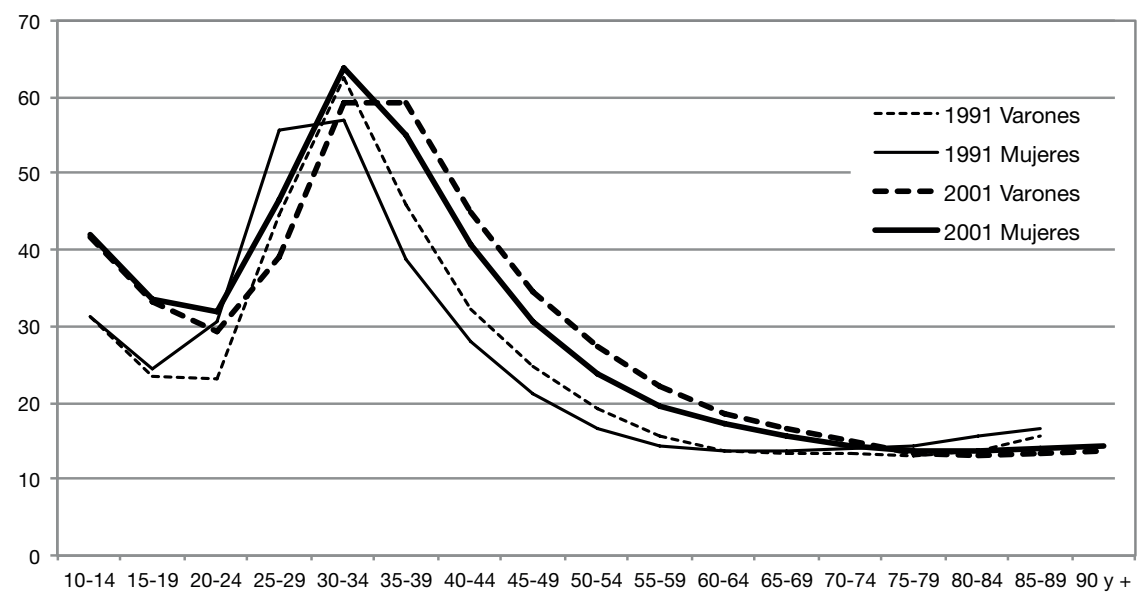

Figura 1. Evolución de las tasas de movilidad residencial metropolitana, según los censos de 1991 y 2001 (\%).

Fuente: elaboración propia a partir de los censos de población de 1991 y 2001.

Los cambios entre 1991 y 2001 parecen estar relacionados con un retraso del calendario de la movilidad, muy apreciable en la misma figura. Las tasas de movilidad de los grupos jóvenes, 25-29 en mujeres y 25-34 en hombres, descendieron ligeramente entre ambos decenios. Sin embargo, las tasas de niños y adultos se incrementaron de forma notable; en algunos grupos, más del $40 \%$. Por último, las tasas de movilidad de los mayores también descendieron un poco. Debemos concluir, por tanto, que los cambios familiares, en muchos casos de parejas con hijos, fueron un componente clave del aumento de la movilidad metropolitana en el periodo analizado ${ }^{15}$. Esta relevancia contrasta con el caso del Reino Unido, donde dos tercios de los movimientos en el año anterior al censo de 2000 fueron individuales (Champion y Coombes, 2007). El aumento de la intensidad y el retraso del calendario de la movilidad se reflejan en la figura 1 como un desplazamiento de las líneas hacia arriba y hacia la derecha ${ }^{16}$.

Pero no solo cambiaron las tasas de movilidad, su intensidad y calendario, sino que también lo hicieron la estructura de edades y sexos de la población

15. A pesar de esto, la figura 2 muestra una disminución del porcentaje de niños en el conjunto de los móviles, debido a la fuerte disminución de la fecundidad durante los años ochenta, por eso en los noventa se producen más cambios familiares, pero de familias con menos hijos.

16. Sin embargo, si calculamos la edad media a la movilidad, comprobaríamos que disminuye. Esto es consecuencia de que la más tardía movilidad de los adultos se ve compensada por el incremento de la movilidad de los niños, que los acompañan en su desplazamiento. Para apreciar el retraso en el calendario, tendríamos que calcular la edad media a la movilidad de los que se mueven por encima de los 20 años. 


\section{Población residente}

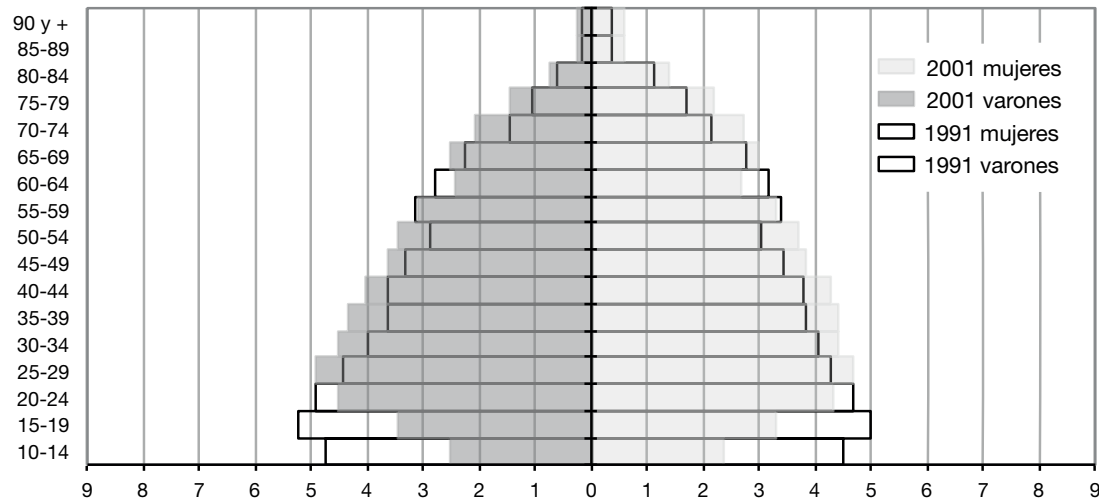

Móviles metropolitanos

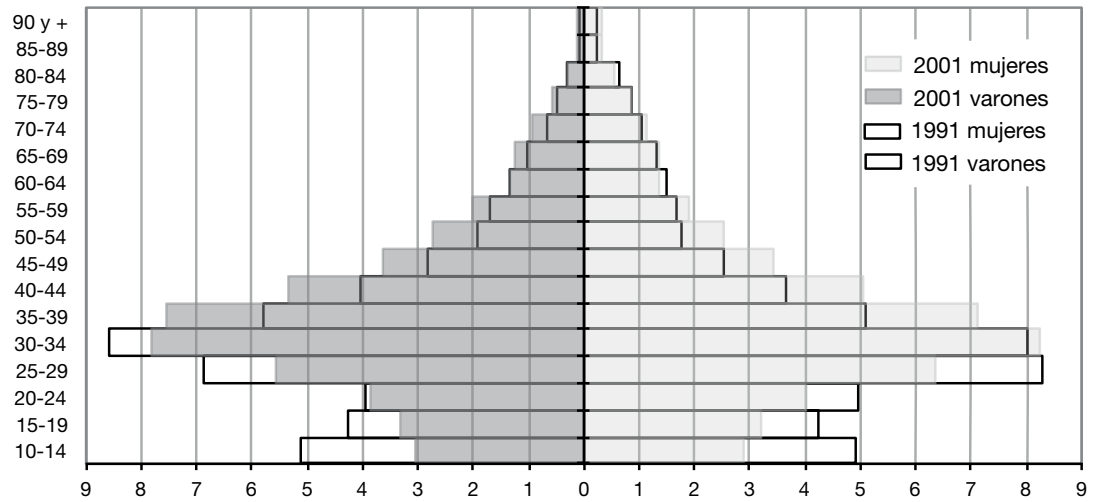

Figura 2. Pirámides de edades y sexos de la población residente y de los móviles metropolitanos en 1991 y 2001 (\%).

Fuente: elaboración propia a partir de los censos de población de 1991 y 2001.

de referencia: la población envejeció, el número y la proporción de adultos aumentó, el de niños y jóvenes menores de 25 años disminuyó (figura 2). De ahí que la proporción que los menores de 35 años representan respecto al total de los móviles disminuya entre ambos periodos.

Como consecuencia, los jóvenes entre 20 y 34 años suponen, en la década de 1990 , una parte mucho menor en el conjunto de la movilidad de la que representaban en la década de 1980: el 36\% frente al $41 \%{ }^{17}$. Frente a este descenso,

17. Disminución que se nota todavía más si excluimos del total a los niños y adolescentes de 10 a 19 años, ya que, en este caso, los jóvenes de 20 a 34 años pasarían de representar el 50\% a representar el $41 \%$. 
la movilidad de los adultos ganó peso. No solamente aumentaron sus tasas, sino que éstas afectaron a un volumen de población absoluta y relativamente mayor.

Si los perfiles de edad de los que se movieron en las décadas de 1980 y 1990 varían notablemente en conjunto, no menos interesantes son las alteraciones de las características de los que se mudan en función del tipo de traslado. Para analizarlas, nos fijaremos en la distribución por edades de las pautas de movilidad, no en las tasas mismas, que son difícilmente comparables, al tener intensidades muy diferentes en cada ámbito. La figura 3 permite observar las variaciones del calendario en el tiempo y por ámbitos, ya que está construida con índices sobre la movilidad media de cada ámbito, con lo que la movilidad media es siempre cien en cada ámbito y periodo.
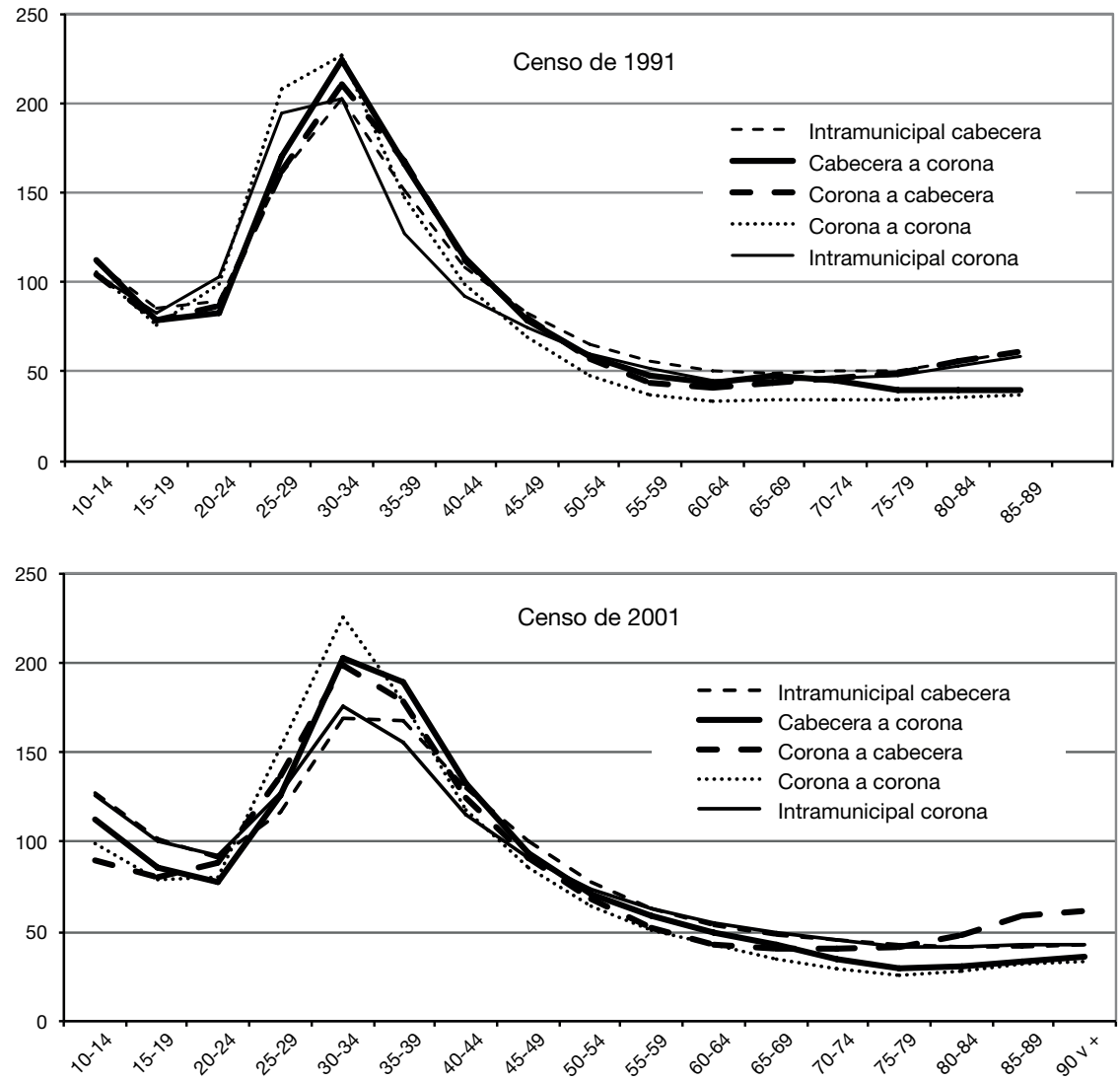

Figura 3. Evolución de la distribución por edades de las tasas de movilidad residencial metropolitana (índices en base 100).

Fuente: elaboración propia a partir de los censos de población de 1991 y 2001.

Nota: los índices están calculados sobre la tasa de movilidad media de cada ámbito. 
La evolución del calendario de la movilidad no siguió las mismas pautas en todos los ámbitos. Se pasa de distribuciones de frecuencias de la movilidad bastante parecidas en todos los ámbitos en el censo de 1991 a distribuciones más diferenciadas en 2001. Aunque, en general, hubo un aumento del peso de la movilidad de los adultos, frecuentemente acompañados de niños, tal cosa ocurrió en mayor medida en los movimientos intramunicipales. Además, en la mayor parte de los ámbitos, la movilidad de los jóvenes descendió respecto a la media. La consecuencia es un cierto efecto de aplanamiento general de las distribuciones, ya que los picos tienden a bajar respecto a la media, mientras que los valles tienden a elevarse. Aplanamiento que es mayor en las dos formas de movilidad intramunicipal y menor en la movilidad de suburbanización.

Recapitulando lo visto hasta ahora, podemos evaluar de qué forma, en el aumento de la movilidad absoluta en el conjunto de las áreas metropolitanas españolas, por tipos o ámbitos de movilidad, se combinan distintos efectos:

- En primer lugar, la movilidad absoluta aumentó porque lo hizo la población afectada, que, como ya se ha señalado, creció más en las coronas suburbanas que en las cabeceras metropolitanas. Este factor explica, sin el concurso de otros, por qué la movilidad intramunicipal en las coronas crece más que la suburbanización (ver tabla 3).

- En segundo lugar, el cambio en las estructuras de edad tiene un efecto contradictorio. La población había envejecido al disminuir la presencia relativa de los menores de 25 años, pero había aumentado el tamaño de los grupos donde más creció la movilidad. Dependiendo de la distribución por edades de la movilidad por ámbitos, el efecto del cambio en la estructura puede ser positivo o negativo.

- En tercer lugar, el efecto del cambio en el calendario de la movilidad tiende a incrementarla, puesto que la movilidad de los jóvenes pierde importancia a favor de la movilidad de los adultos, y esto afectó a una población con menos jóvenes y más adultos. Es decir, el cambio en la estructura de edades y el cambio en el calendario de la movilidad se combinan de modo que, al envejecer a la vez la población y el calendario, la movilidad aumentó.

- Por último, la mayor parte del aumento absoluto de la movilidad se debe al incremento de su intensidad, del número de veces que las personas cambian de residencia a lo largo de su vida en cada ámbito ${ }^{18}$. Esto es especialmente cierto en la movilidad suburbana (tabla 3), pero teniendo en cuenta que se produce en el contexto de un aumento generalizado de la intensidad de la movilidad $^{19}$.

18. La excepción, de nuevo, la constituye la movilidad desde las coronas metropolitanas hasta las cabeceras, donde se produjo un descenso muy marcado, lo que trataremos más adelante.

19. Los índices sintéticos de movilidad no reflejan la medida real en que tal aumento se produce, dado que, como es sabido, los indicadores transversales de los fenómenos demográficos están afectados por los cambios en su calendario. 
Pero, aun sin entrar en la explicación teórica de este aumento de la intensidad de la movilidad, debemos preguntarnos por la incidencia de otros factores estructurales, como puedan ser los cambios en la disposición social.

\section{La movilidad de las distintas categorías sociolaborales}

El punto de partida es el mismo que en el apartado anterior: el aumento generalizado de la movilidad se traslada a cada una de las categorías sociolaborales. $\mathrm{El}$ interés radica en dos matizaciones a esta tónica general. Por una parte, la movilidad no aumentó en la misma medida en todas las categorías. Por otra, aquí también se produjo un cambio estructural (en la estructura productiva y ocupacional, en este caso), y las categorías que diferenciamos variaron su peso dentro de la estructura social metropolitana.

En la tabla 4, se aprecia un crecimiento generalizado y bastante uniforme de la movilidad. Según el censo de 1991, el total de la población cambiaba de residencia 1.513 veces por cada 1.000 personas durante la edad activa (fuesen o no activos), mientras que, según el censo de 2001, cambiaba 1.823 veces.

En relación con estos índices, las distancias se redujeron, y se acercaron a esta media tanto las categorías de mayor como de menor movilidad. Las dos categorías con más elevada movilidad, que son empresarios y autónomos no agrarios y directivos, profesionales y técnicos (por encima de dos cambios por habitante en 2001), experimentaron un aumento de la movilidad, bien en la media o por debajo de la media. Sin embargo, las dos categorías menos móviles registraron el mayor aumento de la movilidad: las clases agrarias y los pensionistas ${ }^{20}$.

A esto hay que sumar que las categorías que más peso ganaron en la estructura social son algunas de las que tienen más alta movilidad. En primer lugar, directivos, profesionales y técnicos, cuyo volumen se multiplicó por dos. Las dos categorías de ocupados con menor movilidad, bien disminuyeron en términos absolutos, como les ocurre a las clases agrarias, bien fueron las que menos crecieron, caso de los trabajadores manuales no agrarios. Por tanto, hubo una generalización de las pautas de alta movilidad adulta, que afectó a todas las categorías, incluidos los no ocupados.

Como consecuencia, el cambio en la estructura de clases tuvo una incidencia notable sobre el aumento de la intensidad de la movilidad que veíamos en la tabla 3. Es decir, en el aumento de la movilidad metropolitana, además de los efectos debidos al aumento del tamaño de la población, del cambio en la estructura de edades y del cambio en el calendario de la movilidad ligado a esta, una parte del aumento restante de la intensidad de la movilidad se debe al cambio en la estructura social de las ciudades metropolitanas.

20. Hay que advertir que los índices de movilidad recogidos en la tabla se refieren a los pensionistas en edad activa, no al conjunto de los pensionistas; de ahí su pequeño número y su disminución. No obstante, la movilidad del total de los pensionistas es también la más baja y solo un poco más alta en relación con la media que la de los pensionistas en edad activa. Por otra parte, la movilidad de los no activos es cercana a la media, dado que, en gran parte, es una movilidad «dependiente» de los activos de su unidad familiar. 
Tabla 4. Evolución de la estructura social en las áreas metropolitanas españolas y la movilidad residencial de cada categoría (población de 20 a 64 años, excluidos inmigrantes)

\begin{tabular}{|c|c|c|c|c|c|c|}
\hline & \multicolumn{3}{|c|}{ Población residente } & \multicolumn{3}{|c|}{ Índice sintético de movilidad } \\
\hline & 1991 & 2001 & $\%$ cambio & 1991 & 2001 & $\%$ cambio \\
\hline Clases agrarias & 263.870 & 225.028 & $-14,7$ & 1.197 & 1.597 & 33,5 \\
\hline Empresarios y autónomos no agrarios & 995.847 & 1.166 .261 & 17,1 & 1.706 & 2.048 & 20,1 \\
\hline Directivos, profesionales y técnicos & 1.267 .288 & 2.501 .106 & 97,4 & 1.763 & 2.042 & 15,8 \\
\hline Empleados administrativos y de servicios & 2.360 .943 & 3.515 .613 & 48,9 & 1.605 & 1.894 & 18,0 \\
\hline Trabajadores manuales no agrarios & 2.085 .097 & 2.423 .057 & 16,2 & 1.451 & 1.796 & 23,8 \\
\hline Otros ocupados & 1.567 .675 & 1.537 .143 & $-1,9$ & 1.717 & 1.984 & 15,5 \\
\hline Parados & 997.572 & 1.039 .073 & 4,2 & 1.449 & 1.709 & 18,0 \\
\hline Pensionistas & 515.313 & 238.964 & $-53,6$ & 1.192 & 1.496 & 25,5 \\
\hline Otros no activos & 4.035 .100 & 3.541 .781 & $-12,2$ & 1.418 & 1.685 & 18,8 \\
\hline Total & 14.088 .705 & 16.188 .026 & 14,9 & 1.513 & 1.823 & 20,5 \\
\hline
\end{tabular}

Fuente: elaboración propia a partir de los censos de población de 1991 y 2001.

Nota: los índices sintéticos de movilidad se refieren a la población entre 20 y 64 años y están expresados por mil habitantes.

Ahora bien, las estructuras sociales no cambian en la misma medida en cabeceras y coronas, entre otras cosas, debido a la propia movilidad residencial entre tales ámbitos. Por eso es necesario estudiar las diferencias en la movilidad por ámbitos de las distintas categorías sociales. Y es que no se debe deducir que esta tendencia a la generalización de la movilidad elimine la importancia que, sobre ella, tienen los factores sociales.

Las diferencias sociales persisten y no solamente se reflejan en los desplazamientos totales, sino que tienen una repercusión diferencial en cada ámbito de movilidad. La figura 4 muestra una comparativa entre las movilidades por edades de dos grupos sociales. Por un lado, hemos agrupado a directivos, profesionales y técnicos, que son la mejor aproximación posible (con los datos de que disponemos) a las clases medias-altas urbanas. Este grupo ha sido el protagonista arquetípico descrito en muchos estudios anglosajones de la suburbanización. De otra parte, agrupamos a trabajadores manuales y no cualificados no agrarios, la tradicional clase obrera urbana. En 2001, ambos grupos tenían un peso parecido en la estructura social. Conjuntamente, suponían la mitad de la población ocupada y cerca de una cuarta parte de la población total. Generalmente, suele asociarse a los obreros con una menor movilidad, ya sea por sus menores posibilidades económicas, por su dependencia del transporte público o por la existencia de lazos comunitarios fuertes en sus barrios de origen. Como vemos, las diferencias sociales siguen dibujando escenarios muy diferentes para trabajadores manuales y profesionales.

Los obreros se trasladan con más frecuencia en las edades jóvenes y, después, su movilidad es bastante menor que la de las clases medias altas. Este patrón es coherente con los datos sobre emancipación, que es más temprana entre los jóvenes de familias trabajadoras que entre los procedentes de hogares 

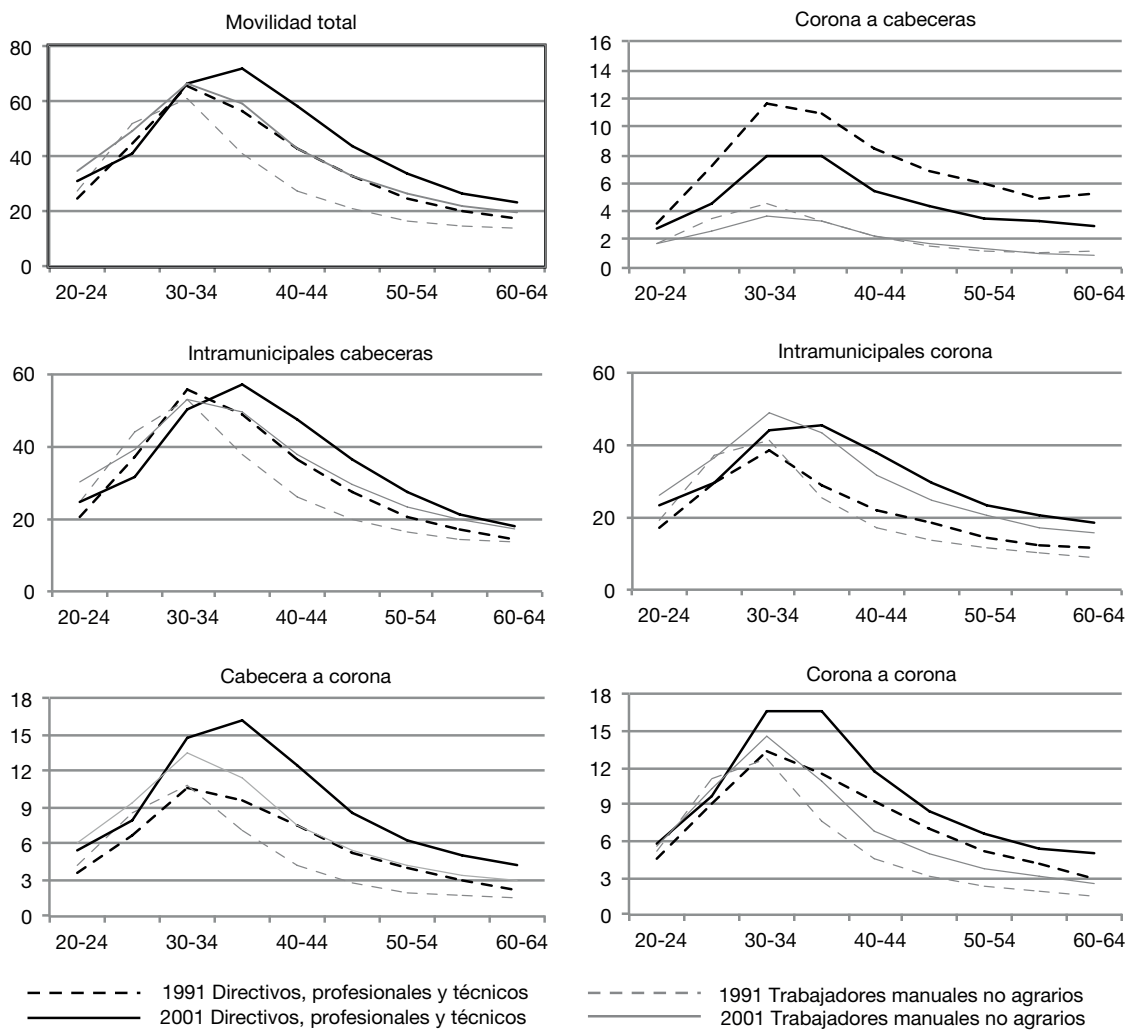

Figura 4. Evolución de las tasas de movilidad de clases medias altas y clase obrera entre los dos periodos analizados, por ámbitos de movilidad (\%).

Fuente: elaboración propia a partir de los censos de población de 1991 y 2001.

de clase media. Estos últimos retrasan su traslado, ya sea por continuar en periodo formativo, ya sea para esperar una mejor vivienda o coyuntura inmobiliaria, pero en todo caso parece una cuestión electiva. En cambio, a partir de los 30 o 35 años, dependiendo del ámbito de movilidad, los patrones por clase social se invierten.

En los traslados de menor recorrido, los intramunicipales, las distancias sociales también se acortan. Obreros y profesionales presentan conductas relativamente próximas. Los obreros presentan mayor movilidad hasta los 34 años, los profesionales lo hacen por encima de esa edad. Llama la atención que la movilidad de los trabajadores manuales, en 2001, en las cabeceras era muy similar a la de los profesionales diez años antes, como si las diferencias fuesen cuestión de un desfase temporal. Sin embargo, las pautas de movilidad posiblemente se diferencian en otros aspectos, ya que, mientras los cambios de la clase obrera se producen en gran parte sin salir del mismo barrio, los de 
los profesionales suponen con más frecuencia traslados entre zonas distintas de la ciudad.

En los movimientos de suburbanización, sin embargo, las distancias entre profesionales y trabajadores manuales se ampliaron en las edades intermedias, entre 30 y 44 años. Este proceso estaba liderado, por tanto, para el conjunto de todas las áreas metropolitanas, por las clases medias altas. Algo que ocurría en mucha menor medida en los movimientos que tienen lugar entre distintos municipios de las coronas. Además, al ser los profesionales la categoría que más aumentó, tanto en términos absolutos como relativos, el desarrollo metropolitano se vio reforzado. No obstante, al aumentar mucho más su presencia en las coronas, como consecuencia del proceso de suburbanización, la estructura espacial de la movilidad tenderá a complejizarse, con lo cual aumentarán los movimientos en las coronas y desde estas hasta las cabeceras ${ }^{21}$. Al aumentar mucho menos la presencia de profesionales en las cabeceras, la suburbanización liderada por estos tenderá a debilitarse y a perder protagonismo a favor de otras categorías sociales, es decir, la suburbanización tiende a generalizarse a todos los grupos.

Sin embargo, la pauta general descrita presenta una excepción notable, la de los que se mueven desde la corona hasta la cabecera. Interpretamos la disminución de este tipo de movilidad, que ya hemos señalado anteriormente, como la consecuencia de la pérdida de peso durante el periodo estudiado de los tradicionales movimientos centrípetos, hacia la ciudad, provenientes de las áreas rurales cercanas. Casi toda la disminución se concentra en el comportamiento de los profesionales. Estos grupos parecen haber sustituido la migración hacia los centros metropolitanos por la movilidad cotidiana pendular, sin cambiar de lugar de residencia. Los trabajadores se mantuvieron en números muy similares, por lo que entre ellos no se habría producido este efecto de sustitución.

Pero, al trabajar sobre datos para el conjunto de las áreas metropolitanas españolas, estamos mezclando dos tipos de desplazamientos muy distintos en esta categoría. En aquellas áreas plenamente consolidadas, con coronas integradas en la dinámica urbana, la vuelta a la cabecera cobra un sentido electivo, de búsqueda de una opción residencial diferente a la suburbana, una vez comprobado lo que ésta ofrece. Autores como Ley (1996) o Caulfield (1994) señalan este deseo de volver a vivir «el centro» como principal detonante de los procesos de renovación urbana (o gentrification). Sin embargo, la mayor parte de las áreas metropolitanas españolas no estaban en este punto en el periodo estudiado, sino más bien en el opuesto. Las cifras del censo de 1991 son reflejo todavía de una fase anterior de concentración urbana.

La tendencia global es, no obstante, la continuidad de las distancias sociales en las pautas de movilidad, a pesar de la generalización de la movilidad. Pare-

21. La presencia relativa de profesionales en las coronas se multiplicó por 2 entre 1991 y 2001 y la de administrativos y otros empleados de los servicios, por 1,5, mientras que, en las cabeceras, lo hicieron por 1,6 y 1,2, respectivamente, mientras otras categorías de ocupados apenas modificaron su presencia relativa. 
ce ocurrir en la movilidad lo mismo que en otros aspectos de la desigualdad social, por ejemplo, en las desigualdades frente a la muerte. Las diferencias en la esperanza de vida y la probabilidad de muerte de ricos y pobres persisten, pese a las mejoras en atención sociosanitaria o en las condiciones de vida de todos los grupos sociales.

\section{Conclusiones}

Como se ha ido viendo a lo largo de estas páginas, el periodo 1980-2001 está marcado por un importante crecimiento de las estructuras urbanas metropolitanas. Un desarrollo del fenómeno metropolitano que se alimenta no solo del aumento de la propensión a la suburbanización, sino también del incremento mismo de la movilidad, que se generalizó. En los años ochenta, los protagonistas destacadísimos fueron los jóvenes y las clases medias. Estos mismos grupos siguieron conservando su primacía, pero la movilidad del resto de la sociedad creció hasta acortar distancias. Esto supone que no solo se diversifican los agentes, sino que las trayectorias también son más complejas. Conviven tendencias centrípetas y, sobre todo, centrífugas, las que constituyen la suburbanización, y son las principales responsables del desarrollo metropolitano. Y aunque aumentaron los cambios intermunicipales, los intramunicipales siguieron siendo los más numerosos. Una vez descrita esta transformación, ¿es posible apuntar sus causas?

Ciertamente, hay una posible explicación de carácter estructural, macroeconómica, de esta evolución: el proceso de financiación de la economía española y el efecto riqueza provocado por el crédito barato y la inversión inmobiliaria que ya empezó en la época estudiada (López y Rodríguez, 2010). Con frecuencia, también se esgrime como explicación el diferencial de precios entre centro y periferia urbana, lo que no se acomoda bien al hecho de que, a pesar de la generalización de la movilidad metropolitana, son los que se sitúan en los escalones más altos de la estructura social los que siguieron protagonizando la suburbanización, al menos para el conjunto de las áreas metropolitanas. Para que las grandes tendencias se impongan, hace falta que haya actores individuales que conjuguen los determinantes estructurales como motivaciones personales, que nunca resultan una mera traslación de las lógicas globales.

En este momento, no estamos en disposición de ofrecer una explicación de cómo se combinan determinantes macro y micro en la evolución del desarrollo urbano y, más en concreto, del proceso de suburbanización. Antes que nada, será necesario completar la descripción de la realidad metropolitana española. Elaborar una tipología de áreas según las características de sus protagonistas o emprender análisis específicos para áreas con estructuras apartadas del modelo centralizado son dos ejemplos de lo que queda por hacer. También es necesario cuantificar los efectos combinados cuya interacción hemos descrito en este trabajo y, por supuesto, extender el análisis a periodos más recientes. $Y$, a partir de la información que se produzca, profundizar en las explicaciones que permitan entender la conducta de los actores sin reducirlos a Homo economicus. Entender a los sujetos, no ya reaccionando a los cambios en el 
mercado inmobiliario metropolitano, sino interactuando en el espacio social de la ciudad metropolitana.

\section{Referencias bibliográficas}

Alonso, William (1964). Location and Land Use. Cambridge: Harvard University Press.

ArizagA, M. Cecilia (2004). «Espacialización, estilos de vida y clases medias: Procesos de suburbanización en la Región Metropolitana de Buenos Aires». Perfiles Latinoamericanos, 25, 43-58.

Burriel de Orueta, Eugenio Luis de; Salom Carrasco, J. y Delios España, E. (1998). «Continuidad y cambio en las pautas territoriales del crecimiento demográfico valenciano: Análisis del periodo 1991-1996». Cuadernos de Geografía, 63, 103-137.

Caulfield, J. (1994). City Form and Everyday Life: Toronto's Gentrification and Critical Social Practice. Toronto: University of Toronto Press.

Champion, Tony y CoOmbes, Mike (2007). «Using the 2001 census to study human capital movements affecting Britain's larger cities: insights and issues». Journal of the Royal Statistical Society A, 170 (2), 447-467.

CHAMPION, Tony y FISHER, Tania (2003). "The social selectivity of migration flows affecting Britain's larger conurbations: An analysis of the 1991 census regional migration tables». Scottish Geographical Journal, 119 (3), 229-246.

DematTeis, Giuseppe (1998). «Suburbanización y periurbanización: Ciudades anglosajonas y ciudades latinas». En: MonCLús, Francisco Javier (ed.). La ciudad dispersa. Barcelona: Centro de Cultura Contemporánea de Barcelona.

ENTRENA, Francisco (2005). «Procesos de periurbanización y cambios en los modelos de ciudad: Un estudio europeo de casos sobre sus causas y consecuencias». Papers: Revista de Sociologia, 78, 59-88.

FERIA, José M. (2009). «Problemas de definición de las áreas metropolitanas españolas». Boletín de la Asociación de Geógrafos Españoles, 38, 85-99.

- (2010). "La delimitación y organización espacial de las áreas metropolitanas españolas: una perspectiva desde la movilidad residencia-trabajo». Ciudad y Territorio. Estudios Territoriales, XLII (164), 189-210.

FERrÁs SEXTO, C. (2011). «Da aldea ao suburbio: Cambios demográficos e territoriais en galicia, 1990-...». Revista Galega de Economía: Publicación Interdisciplinar da Facultade de Ciencias Económicas e Empresariais, 20 (2), 11-30.

García COll, Arlinda (2009). "Migraciones interiores y transformaciones territoriales». En: POnS, J. et al. (eds.). Territorio y movilidad interior de la población en España. Pamplona: EUNSA, 13-40.

García-Palomares, J.C. y Pozo Rivera, E. (2010). «Movimientos migratorios en la comunidad de Madrid: Unos flujos intensos y complejos (1991-2006)». Boletín de la Asociación de Geógrafos Españoles, 53, 89-119.

GlaEsER, Edward L. y KAHN, Matthew E. (2003). «Sprawl and Urban Growth. Discussion Papers, 2004, Harvard Institute of Economic Research.

HARRIS, Richard y LARKHAM, Peter J. (1999). «Suburban foundation, form and function». En: HARRIS, Richard y LARKHAM, Peter J. (eds.). Changing suburbs: foundation, form and function. Londres: Spon.

Indovina, F. (2004). «La ciudad difusa». En: MARTín Ramos, A. (ed.). Lo urbano en 20 autores contemporáneos. Barcelona: Edicions UPC, 49-59. 
KABISCH, Nadja y HAASE, Dagmar (2011). «Diversifying European Agglomerations: Evidence of Urban Population Trends for the 21st Century». Population, Space and Place, 17, 236-253.

KIM, S. (2007). «Changes in the nature of urban spatial structure in the United States, 1890-2000». Journal of Regional Science, 47, 273-287.

LEICHENKO, R.M. y SOLECKI, W.D. (2005). "Exporting the american dream: The globalization of suburban consumption landscapes». Regional Studies, 39 (2), 241-253.

LeY, David (1996). The New Middle Class and the Remaking of the Central City. Oxford: Oxford University Press.

LÓPEZ, Isidro y RODRÍGUEZ, Emmanuel (2010). Fin de ciclo: Financiarización, territorio y sociedad de propietarios en la onda larga del capitalismo hispano (1959-2010). Madrid: Traficantes de Sueños.

LÓPEZ GAY, Antonio y RECAÑO VALVERDE, Joaquín (2008). «La renovación sociodemográfica de un centro urbano maduro: perfiles migratorios y filtros residenciales en la ciudad de Barcelona». Scripta Nova, XII (270), 130.

MieszKOwsKi, Peter y MiLls, Edwin S. (1993). "The Causes of Metropolitan Suburbanization». The Journal of Economic Perspectives, 7, (3), 135-147.

Ministerio de Vivienda (2006). Atlas estadístico de las áreas urbanas de España. Madrid: Ministerio de Vivienda.

Miralles-Guasch, Carme; Donat, Carles y Barnada, Jaume (2007). «Habitatge i mobilitat residencial a la Regió Metropolitana i a la Província de Barcelona». Papers: Regió Metropolitana de Barcelona: Territori, Estratègies, Planejament, 46, 9-46.

Módenes Cabrerizo, Joan Antoni (2001). «Relacions socioterritorials i mobilitat residencial a l'àrea de Barcelona». Revista Catalana de Sociologia, 14 (2001), 43-56.

MongIN, Olivier (2006). La condición urbana: La ciudad a la hora de la mundialización. Buenos Aires: Paidós.

MORRISON, P.S. y ClARK, W.A.V. (2011). «Internal migration and employment: Macro flows and micro motives». Environment and Planning A, 43 (8), 1948-1964.

NEL.LO, Oriol (2007). «La tercera fase de metropolitanización en España». En: Rullán, O. (ed.). Los procesos urbanos postfordistas. Mallorca: Asociación de Geógrafos Españoles.

PUJADAS, Isabel (2009). «Movilidad residencial y expansión urbana en la Región Metropolitana de Barcelona, 1982-2005». Scripta Nova: Revista Electrónica de Geografía y Ciencias Sociales, XIII, 290.

PUJADAS, Isabel y GARCÍA-COLL, Arlinda (2007). «Movilidad residencial y polarización social: La diferenciación social de los nuevos espacios residenciales en la Región Metropolitana de Barcelona». Espacios públicos-espacios privados: Un debate sobre el territorio. Santander: AGE-Universidad de Cantabria.

Real ACAdemia Española (2001). Diccionario de la Lengua Española. 22a ed. Madrid: Espasa Calpe.

Rossi, Peter. H. (1980). Why families move? EE. UU.: Sage Publications, 1955.

RuIZ, Francisco (2012). AUDES: Áreas urbanas de España [en línea]. <http://alarcos. esi.uclm.es/per/fruiz/audes/index.htm> [Consulta: 4 abril 2012].

SuSINO, Joaquín (2010). «La movilidad residencial diferencial en la reconfiguración metropolitana». En: FERIA, J. M. y AlBERTOS, J. M. La ciudad metropolitana en España: Procesos urbanos en los inicios del siglo XXI. Madrid: Thomson-Civitas, 149-174. 
- (2011). «La evolución de las migraciones interiores en España: Una evaluación de las fuentes demográficas disponibles». Papers: Revista de Sociología, 96 (3), 853-881. Van den Berg, L.; DrewetT, R.; KlaAsen, L.H.; Rossi, A. y VijverberG, C.H.T. (1982). Urban Europe: A Study of Growth and Decline. Oxford: Pergamon.

VICENTE, Joan (2003). "¿Nuevas palabras, nuevas ciudades?». Revista de Geografía, 2, 79-103.

Yu, Tyler; Johnson, Victoria y ZHAnG, Miranda (2004). «Urban Sprawl: Myth or Reality?" Journal of the American Academy of Business, 4, 1-8.

ZeBIK, Grzegorz (2011). «Typology of Suburban Communities in Poland». Bulletin of Geography. Socio-Economic Series, 16, 173-188. 